\title{
Effects of teriparatide in Chinese and Caucasian women with osteoporosis: bridging study on efficacy
}

This article was published in the following Dove Medical Press journal:

Clinical Interventions in Aging

\author{
Zhongjian $\mathrm{Xie}^{1}$ \\ Yun Chen ${ }^{2}$ \\ Sirel Gurbuz ${ }^{3}$ \\ Bin Zhang ${ }^{2}$ \\ Yujie $\mathrm{Li}^{2}$ \\ Fan $\mathrm{Bai}^{2}$ \\ Yu Chen ${ }^{2}$
}

'Department of Metabolism and Endocrinology, Hunan Provincial Key Laboratory of Metabolic Bone Diseases and National Clinical Research Center for Metabolic Diseases, The Second Xiangya Hospital, Central South University, Changsha, Hunan, China; ${ }^{2}$ Eli Lilly Suzhou Pharmaceutical Co., Ltd, Shanghai, People's Republic of China; ${ }^{3}$ Eli Lilly and Company, Indianapolis, IN, USA
Correspondence: Zhongjian Xie No.139, Mid Renmin Road, Changsha, Hunan 4I00I I, People's Republic of China

Tel +86 73I 85292152

Email zhongjian.xie@csu.edu.cn
Objective: To bridge the efficacy and compare the safety of the 24-week teriparatide treatment in a Chinese osteoporosis study (NCT00414973) to a large international trial (FPT, NCT00670501) to determine whether long-term results from the international study were applicable to Chinese patients.

Methods: In this post-hoc analysis, a propensity score matching method was used to select patients with similar baseline characteristics. Patients were female with osteoporosis at high risk of fracture, aged $\geq 55$ years, and had no history of rheumatoid arthritis or corticosteroid use. Outcomes included percentage changes in lumbar-spine bone mineral density (LS-BMD) from baseline to 24 weeks, safety in matched-pair patients, and long-term percentage changes in LS-BMD and fragility fracture incidence in the matched fracture prevention trial (FPT) population. The determination of the acceptability of bridging results was based on the International Conference on Harmonization E5 guidelines.

Results: A total number of 228 patients from each study were matched and paired. Patients were similar at baseline ( $P$-values $>0.33)$ except for ethnicity $(98 \%$ Caucasian for FPT). For changes in LS-BMD from baseline to week 24 , treatment with teriparatide showed significantly greater increases $(P$-values $<0.001$; least-squares mean difference: $5.0 \%$ in the Chinese study and $5.4 \%$ in FPT) than comparator (calcitonin/placebo). The safety profiles over 24 weeks were similar between two studies. For matched-pair FPT patients, long-term changes in LS-BMD were significantly greater (least-squares mean difference: $11.5 \%, P<0.001$ ) and the fragility fracture rate was marginally lower in the teriparatide group compared with the placebo group (13.1\% vs $22.3 \%, P=0.070)$.

Conclusion: Assuming similar pharmacokinetic profiles for teriparatide between populations, comparable increases in LS-BMD and consistent safety profiles within 24 weeks of the treatment suggest long-term LS-BMD results from the FPT may be applicable to Chinese population.

Keywords: osteoporosis, teriparatide, bridging, lumbar spine-bone mineral density, LS-BMD, fracture prevention trial

\section{Introduction}

Osteoporosis is a systemic skeletal disease that leads to an increased risk of fracture. The osteoporosis prevalence for women in nine industrialized countries ranged from $9 \%$ to $38 \%{ }^{1}$ and it is reported the prevalence of osteoporosis in China increased over the past decades and reached 28\% during the period spanning 2012-2015. ${ }^{2}$ Teriparatide, the 1-34 N-terminal fragment of parathyroid hormone, is an anabolic medication that increases bone mineral density (BMD) and improves bone quality by stimulating 
both bone formation and bone resorption. ${ }^{3}$ Compared to placebo, teriparatide treatment reduces risk of vertebral ${ }^{4-6}$ and nonvertebral ${ }^{7}$ fractures in postmenopausal women with osteoporosis.

One-year fracture risk can be equally well predicted in Caucasian, Blacks, Hispanics, Native Americans, and Asians using BMD ${ }^{8}$ Although the efficacy and safety of teriparatide have been assessed in randomized, controlled trials of men and women with osteoporosis for up to 21 months, study populations were largely Caucasian. ${ }^{4-6}$ There is no data showing the comparison in the response of teriparatide between Chinese and Caucasian. Therefore, it is important to know whether the efficacy and safety of teriparatide treatment in Chinese and Caucasian patients with osteoporosis are comparable. The International Conference of Harmonization (ICH) E5 guidelines on ethnic factors in the acceptability of foreign clinical data ${ }^{9}$ allow investigators to use bridging studies to extrapolate data from large foreign studies to smaller domestic trials. This strategy has been used to evaluate osteoporosis therapies, including raloxifene, alendronate, and risendronate. ${ }^{10}$

The goal of our post-hoc analysis was to compare efficacy and safety of 24 weeks of teriparatide treatment in paired Chinese and Caucasian patients with similar baseline characteristics from two studies. If the efficacy of teriparatide was shown to be similar in the matched pairs at 24 weeks, this analysis would support the bridging of data between the Chinese osteoporosis study ${ }^{11}$ and the international fracture prevention trial (FPT), ${ }^{12}$ thus allowing for a reasonable estimate of long-term lumbar spine-bone mineral density (LS-BMD) change and risk reduction of new fractures in Chinese women with osteoporosis. We hypothesize that efficacy and safety between matched Chinese and Caucasian patients will show similar efficacy and safety at 24-weeks.

\section{Materials and methods Study designs}

Response to teriparatide in Chinese and Caucasians was evaluated by selecting patients from two randomized trials. The Chinese osteoporosis study (ClinicalTrials.gov identifier NCT00414973) was an open-labeled, multicenter, active comparator, randomized phase III study. It was carried out in 10 study centers and included 362 postmenopausal Chinese women and men with established osteoporosis. ${ }^{11}$ Patients were randomly assigned to receive teriparatide $20 \mu \mathrm{g}$ once daily or calcitonin $200 \mathrm{IU}$ once daily. Efficacy was assessed by absolute and percent changes in LS-BMD and hip BMD, and changes in biochemical bone markers (osteocalcin; OC) after 24 weeks of treatment. ${ }^{11}$

The study for comparison, the FPT (ClinicalTrials.gov identifier NCT00670501), took place at 99 centers in 17 counties that included 1,637 postmenopausal women with prior vertebral fracture, of whom $98.5 \%$ were Caucasian. ${ }^{12}$ Patients were randomly assigned to teriparatide treatment (20 or $40 \mu \mathrm{g}$ once daily) or placebo for a median of 19 months. Efficacy was assessed by radiographic and clinical vertebral fracture, nonvertebral fracture, changes in BMD in spine and hip and changes in the bone marker including procollagen 1 carboxyterminal propeptide (P1CP).

Overview of both study designs are shown in Table 1.

\section{Outcomes}

The short-term efficacy of teriparatide was evaluated in matched Chinese and Caucasian patients based on absolute and percent changes in mean LS-BMD from baseline to week 24. LS-BMD for both studies was measured by dual-energy X-ray absorptiometry with the use of Hologic (Hologic; Marlborough, MA, USA), Lunar (GE Healthcare; E Healthcare, Little Chalfont, UK), or Norland (Swissray; Piscataway, NJ, USA) scanners. Manufacturer-specific BMD data, not scannergenerated standardized data, were collected. Standardized BMD (sBMD) data were the basis for any statistical analysis. ${ }^{13}$ The following standardization methodology was used:

- For Hologic instruments: $\operatorname{sBMD}\left(\mathrm{mg} / \mathrm{cm}^{2}\right)=1,000$ $\left[1.091 \times \mathrm{BMD}_{\text {Hologic }}-0.016\right]$

- For Lunar instruments: $\operatorname{sBMD}\left(\mathrm{mg} / \mathrm{cm}^{2}\right)=1,000$ [BMD $\left.{ }_{\text {Lunar }}-0.0552\right]$

- For Norland instruments: $\operatorname{sBMD}\left(\mathrm{mg} / \mathrm{cm}^{2}\right)=1,000$ $\left[1.005 \times \mathrm{BMD}_{\text {Norland }}+0.070\right]$.

Efficacy measurements also included bone turnover markers (OC in the Chinese study, P1CP in the FPT). Safety was assessed by the frequency and proportion of patients in each study who experienced a treatment-emergent adverse event (TEAE) and serious adverse event (SAE). Laboratory tests included serum, calcium, phosphorus, hepatic enzyme, renal function, and uric acid analyses. Changes in mean LSBMD and the rate of fracture after 24 months treatment for matched patients from the FPT were evaluated. In addition, the entire FPT and Chinese study populations were pooled for an analysis that estimated the relative risk reduction for fracture of teriparatide compared to comparator.

\section{Statistical analysis}

To make the patients comparable, only those who met the selection criteria for both the FPT and the Chinese study were considered. Therefore, patients who were female with 
Table I Overview of study designs

\begin{tabular}{|c|c|c|}
\hline & Chinese study & FPT \\
\hline Design & $\begin{array}{l}\text { - Chinese, phase III, multicenter, open-label, active } \\
\text { comparator, randomized study } \\
\text { - I0 sites, I country (China), I00\% Chinese } \\
\text { - Duration: } 24 \text { weeks of treatment }\end{array}$ & $\begin{array}{l}\text { - Global, phase III, multicenter, double-blind, } \\
\text { placebo-controlled, randomized study } \\
\text { - } 99 \text { centers, } 17 \text { countries, } ~ 98 \% \text { Caucasian } \\
\text { - Duration: median } 19 \text { months of treatment }\end{array}$ \\
\hline Inclusion criteria & $\begin{array}{l}\text { - Ambulatory men (aged } 40-85 \text { years) or women } \\
\text { (aged } 55-85 \text { years and at least } 3 \text { years postmenopause) } \\
\text { - Established osteoporosis based on experiencing } \\
\text { a fragility fracture prior to enrollment or T-score } \\
\text { BMD }<2.5 \text { at LS or hip }\end{array}$ & $\begin{array}{l}\text { - Ambulatory women aged } 35-80 \text { years and at least } 5 \text { years } \\
\text { postmenopause } \\
\text { - Minimum of one moderate or two mild atraumatic } \\
\text { vertebral fractures prior to enrollment. For those with }<2 \\
\text { moderate fractures, or a T-score BMD of }<1.0 \text { at } \\
\text { LS or hip }\end{array}$ \\
\hline Exclusion criteria & $\begin{array}{l}\text { - Disease or medication (eg, corticosteroid) that affect } \\
\text { bone metabolism } \\
\text { - Impaired renal/hepatic function } \\
\text { - Skeletal radiotherapy } \\
\text { - Malignant neoplasm within } 5 \text { years }\end{array}$ & $\begin{array}{l}\text { - Disease or medication (eg, corticosteroid) that affects } \\
\text { bone metabolism } \\
\text { - Impaired renal/hepatic function } \\
\text { - Urolithiasis within } 5 \text { years } \\
\text { - Drug or alcohol abuse }\end{array}$ \\
\hline $\begin{array}{l}\text { Treatment and } \\
\text { sample size }\end{array}$ & $\begin{array}{l}\text { - Teriparatide } 20 \mu \mathrm{g} \text { once daily }(\mathrm{N}=242) \text { administered via } \\
\text { subcutaneous injection } \\
\text { - Salmon calcitonin } 200 \mathrm{IU} \text { once daily administered } \\
\text { intranasally }(\mathrm{N}=120) \\
\text { - All patients received calcium } 500-650 \mathrm{mg} \text { and vitamin D } \\
200-400 \mathrm{IU} \text { daily }\end{array}$ & $\begin{array}{l}\text { - Teriparatide } 20 \mu \mathrm{g}(\mathrm{N}=54 \mathrm{I}) \text { or } 40 \mu \mathrm{g}(\mathrm{N}=552) \text { once daily } \\
\text { administered subcutaneously } \\
\text { - Placebo ( } \mathrm{N}=544) \\
\text { - All patients received calcium I,000 mg and vitamin D } \\
400-\mathrm{I}, 200 \mathrm{IU} \text { daily }\end{array}$ \\
\hline $\begin{array}{l}\text { Primary efficacy } \\
\text { endpoint }\end{array}$ & $\begin{array}{l}\text { - Percent change in mean LS-BMD from baseline to } \\
\text { week } 24\end{array}$ & $\begin{array}{l}\text { - Reduction in new vertebral fractures following } 3 \text { years } \\
\text { of treatment }\end{array}$ \\
\hline $\begin{array}{l}\text { Selected secondary } \\
\text { efficacy endpoints }\end{array}$ & $\begin{array}{l}\text { - Assess safety of teriparatide and calcitonin over } \\
24 \text { weeks in the treatment of men and women } \\
\text { (each gender analyzed separately) as determined by } \\
\text { physical examination, vital signs, clinical laboratory data, } \\
\text { and reports of adverse events }\end{array}$ & $\begin{array}{l}\text { - Establish the effect of long-term treatment with } \\
\text { teriparatide vs placebo on LS-BMD } \\
\text { - Assess population pharmacokinetics of teriparatide } \\
\text { - Establish the safety of long-term administration } \\
\text { of teriparatide }\end{array}$ \\
\hline $\begin{array}{l}\text { Primary and notable } \\
\text { secondary results }\end{array}$ & $\begin{array}{l}\text { - Teriparatide was found to be superior to calcitonin } \\
\text { in increasing percent change in mean LS-BMD in } \\
\text { postmenopausal women } \\
\text { - Both treatments were safe and well tolerated in } \\
\text { this population }\end{array}$ & $\begin{array}{l}\text { - Treatment with teriparatide: } \\
\text { - Decreased the risk of vertebral and nonvertebral } \\
\text { fractures } \\
\text { - Increased vertebral, femoral, and total-body BMD } \\
\text { - Was well tolerated }\end{array}$ \\
\hline
\end{tabular}

Abbreviations: BMD, bone mineral density; FPT, fracture prevention trial; LS, lumbar spine; LS-BMD, lumbar spine-bone mineral density.

osteoporosis at high risk of fracture, aged $\geq 55$ years, and had no history of rheumatoid arthritis or use of corticosteroids were included for matching.

Following the initial trimming, a propensity score (PS) matching method was used to generate matched-pair patients (one patient from each study) that balanced baseline characteristics between ethnic groups. All key unbalanced characteristics (including baseline age, weight, height, body mass index, smoking status, previous osteoporosis medication usage and baseline LS-BMD) were included in the PS model. A 1:1 (Chinese:Caucasian) greedy matching algorithm without replacement and with a specified caliper distance of 0.15 was used to identify matched-pair patients.

The balance of the matched pairs from the two studies was determined by hypothesis testing (two-sample $t$-test for continuous variable and chi-squared test for categorical variables) or by assessing the standardized difference, which compares the difference in means in units of the pooled SD. A standardized difference of 0.1 was taken to indicate a negligible difference in the mean or prevalence of a covariate between two studies. ${ }^{14}$

Change in mean LS-BMD from baseline to post-baseline visit within each treatment arm was tested by paired $t$-test. The difference between teriparatide and comparator groups in LS-BMD was tested by analysis of covariance adjusted for investigator and baseline LS-BMD. Least-squares mean and $95 \%$ CI were provided.

The frequency and proportion of patients with TEAEs/ SAEs through week 24 were summarized using preferred terms of the Medical Dictionary for Regulatory Activities (MedDRA; version 12.0$)$. The relative risk $(95 \% \mathrm{CI})$ was provided. Changes from baseline to week 24 in standard laboratory 
measures and in bone biomarker values was tested by Wilcoxon signed rank test. The difference between teriparatide and comparator groups was tested by Wilcoxon rank sum test.

The difference between teriparatide and comparator groups in the rate of fracture from baseline to month 19 was analyzed by chi-squared test. The relative risk (95\% CI) was provided. Further, we combined all study data from the two studies to determine the difference in fracture at endpoint for teriparatide versus comparator groups. The OR, 95\% CI, and $P$-values were provided by simple logistic regression.

The two-sided significance level of 0.05 was used. Due to the exploratory nature of this analysis, no adjustments for multiplicity were made. Statistical comparisons were accomplished using SAS software (version 9.2; SAS Institute Inc., Cary, NC, USA).

\section{Results}

A total of 228 patients each from the Chinese study and the FPT were matched based on baseline characteristics (Figure 1). Matched patients from the Chinese study included 148 randomized to teriparatide and 80 to calcitonin, while those from the FPT included 107 randomized to teriparatide and 121 to placebo. In the Chinese study, paired patients were Chinese and had a median study duration of 24.3 weeks (5.7 months). In the FPT, 97.8\% of paired patients were Caucasian (1.32\% East Asian and 0.88\% Hispanic) and had a median study duration of 81.6 weeks (19.0 months). Except for ethnicity, baseline characteristics of Chinese and
Caucasian patients were similar in patients selected using the PS method (Table 2). All $P$-values were $>0.33$ and all standard differences were $<10 \%$.

\section{Short-term efficacy (24 weeks following randomization)}

In both the Chinese and Caucasian patients, LS-BMD in the teriparatide groups increased significantly compared with baseline (6.4\% for the Chinese study and $8.6 \%$ for the FPT, $P<0.001$ in both groups) (Table 3 ). For the primary efficacy endpoint, the 24-week teriparatide treatment showed significantly greater increases in LS-BMD $(P<0.001)$ for both absolute and percent change from baseline compared to either comparator (calcitonin or placebo) in both Chinese and Caucasian women with osteoporosis at high risk of fracture. The least-squares mean $(95 \% \mathrm{CI})$ of absolute change difference between the teriparatide group and the calcitonin/ placebo group were $33.9 \mathrm{mg} / \mathrm{cm}^{2}$ (95\% CI: $\left.22.4-45.4\right)$ in the Chinese study and $39.9 \mathrm{mg} / \mathrm{cm}^{2}$ (95\% CI: 20.7-59.0) in the FPT $(P<0.001$ in both studies). The least-squares mean on percent change difference in LS-BMD between the teriparatide group and the calcitonin/placebo group were 5.0\% (95\% CI: 3.2-6.7) in the Chinese study and 5.4\% (95\% CI: $2.5-8.2)$ in the FPT $(P<0.001$ in both studies $)$.

\section{Biomarkers: $\mathrm{OC}$ and PICP}

In the Chinese study, the bone formation biomarker of interest was OC. In 200 out of $228(88 \%)$ patients, the
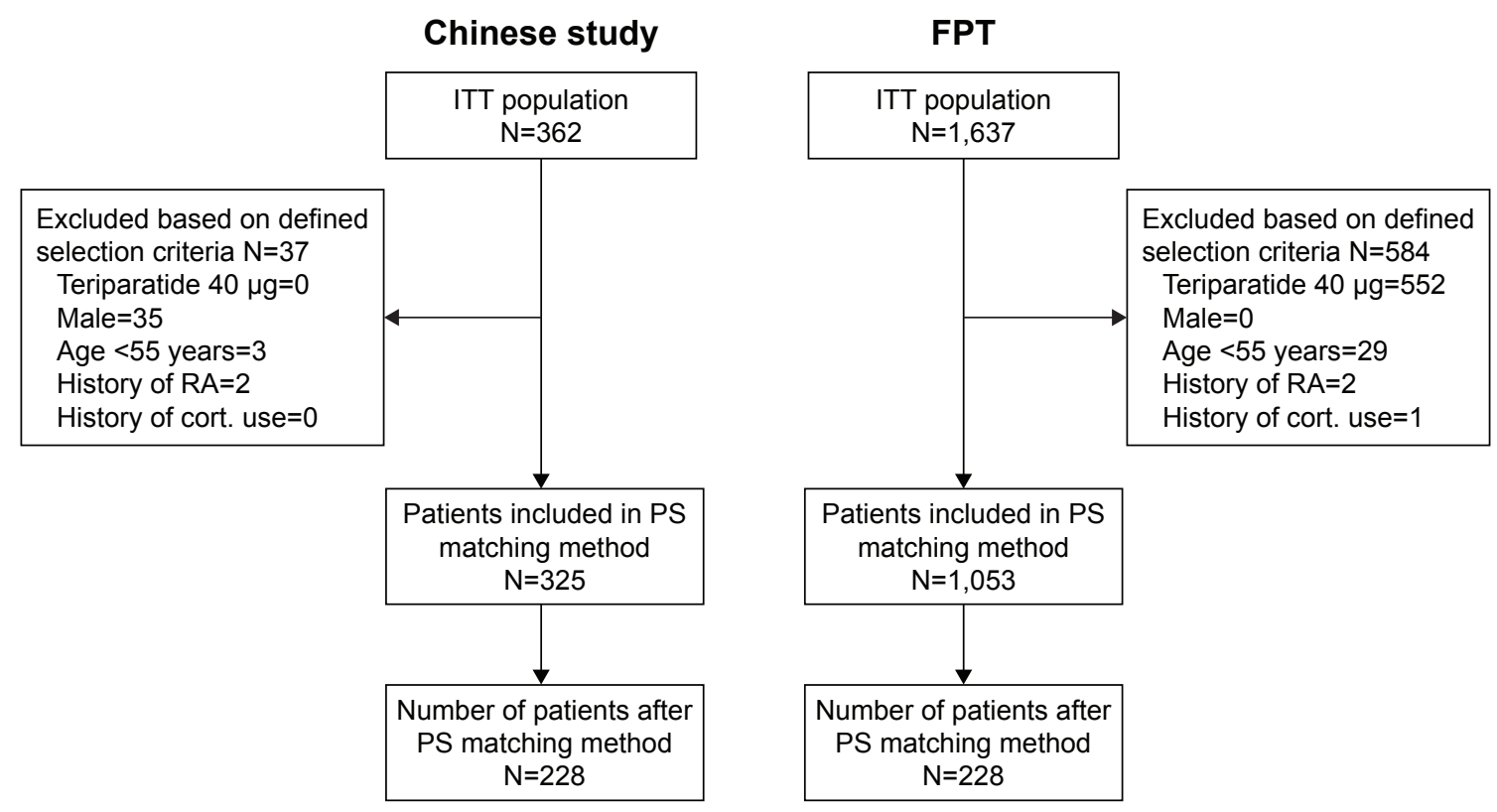

Figure I Patient flow resulting from predetermined criteria to select patients eligible for matching. Abbreviations: cort, corticosteroid; FPT, global fracture prevention trial; ITT, intent-to-treat; PS, propensity score; RA, rheumatoid arthritis. 
Table 2 Baseline characteristics of matched-pair patients from the Chinese study and from the FPT

\begin{tabular}{|l|l|l|l|l|}
\hline & $\begin{array}{l}\text { Chinese study } \\
\mathbf{( N = 2 2 8 )}\end{array}$ & $\begin{array}{l}\text { FPT } \\
(\mathbf{N}=\mathbf{2 2 8})\end{array}$ & P-value $^{\text {a }}$ & Standard difference \\
\hline Age, years, mean (SD) & $69.68(6.83)$ & $69.73(7.02)$ & 0.938 & 0.01 \\
\hline Weight, kg, mean (SD) & $57.63(8.74)$ & $58.42(8.60)$ & 0.335 & 0.09 \\
\hline Height, cm, mean (SD) & $154.00(6.04)$ & $154.23(6.08)$ & 0.681 & 0.04 \\
\hline BMI, kg/m², mean (SD) & $24.30(3.43)$ & $24.58(3.52)$ & 0.385 & 0.08 \\
\hline Alcohol use, yes, N (\%) & $0(0)$ & $0(0)$ & $>0.999$ & 0.00 \\
\hline Smoking (yes), N (\%) & $3.0(1.3)$ & $3.0(1.3)$ & $>0.999$ & 0.00 \\
\hline Previous OP medication, yes, N (\%) & $8(3.5)$ & $10(4.4)$ & 0.631 & 0.05 \\
\hline LS-BMD (mg/cm $\left.{ }^{2}\right)$ mean (SD) & $723.3(\mathrm{Il})$ & 0.946 & 0.01 \\
\hline
\end{tabular}

Note: ${ }^{P}$-value: two-sample $t$-test for continuous variable, chi-squared test for categorical variable.

Abbreviations: BMI, body mass index; FPT, fracture prevention trial; LS-BMD, lumbar spine-bone mineral density; OP, osteoporosis.

OC data had been collected from baseline to week 24 . The median of the percent change from baseline was 139\% in the teriparatide group and $-6 \%$ in the calcitonin group, for a significantly different magnitude of change $(P<0.001)$. In the FPT, the biomarker of interest was P1CP. In 62 out of 228 (27\%) patients, the P1CP data changed from baseline to week 24 . The median of the percent change from baseline was $10.1 \%$ in the teriparatide group and $-3.5 \%$ in the placebo group. This difference was not statistically significant. The median values of both biomarkers increased numerically in the teriparatide treatment groups compare with comparators in both studies (Table not shown).

\section{Short-term safety ( 24 weeks following randomization)}

During the 24-week treatment period, one death was reported in all matched-pair patients from placebo group in FPT (Table 4). SAEs were reported in $4.7 \%$ of the patients randomized to teriparatide and $1.3 \%$ of the patients assigned to calcitonin in the Chinese study. For FPT, 7.5\% of teriparatide-treated patients and $9.9 \%$ of placebo-treated patients in matched patients reported SAEs. The percentage of patients with $\geq 1$ TEAE was $32.4 \%$ and $27.5 \%$ in the teriparatide and calcitonin groups, respectively, in the Chinese study (RR: 1.18 ; 95\% CI: 0.77-1.80). In FPT, patients with $\geq 1$ TEAE were reported between $66.4 \%$ and $65.3 \%$ in the teriparatide and placebo groups, respectively (RR: 1.02; 95\% CI: 0.84-1.23). The adverse event of "blood uric acid increased" was reported in eight patients (5.4\%) randomized to the teriparatide group but none in calcitonin group in the Chinese study. The adverse event of "urinary tract infection" was reported in seven patients from teriparatide $(6.5 \%)$ and placebo (5.8\%) groups, respectively, in the FPT. The trend of common TEAEs in the Chinese study was similar to that in the FPT in the 6-month follow-up period after randomization. In teriparatide-treated Chinese and Caucasian patients,

Table 3 Change in lumbar spine-bone mineral density from baseline to week 24 for matched-pair patients by treatment and by study

\begin{tabular}{|c|c|c|c|c|c|c|}
\hline & \multicolumn{3}{|l|}{ Chinese study } & \multicolumn{3}{|l|}{ FPT } \\
\hline & $\begin{array}{l}\text { Teriparatide } \\
(\mathbf{N}=\mid \mathbf{4 8})\end{array}$ & $\begin{array}{l}\text { Calcitonin } \\
(\mathbf{N}=\mathbf{8 0})\end{array}$ & $\begin{array}{l}\text { Difference, least- } \\
\text { squares mean } \\
(95 \% \mathrm{Cl}) \mathbf{P} \text {-value }\end{array}$ & $\begin{array}{l}\text { Teriparatide } \\
(\mathbf{N}=107)\end{array}$ & $\begin{array}{l}\text { Placebo } \\
(N=12 \text { I) }\end{array}$ & $\begin{array}{l}\text { Difference, least- } \\
\text { squares mean } \\
(95 \% \mathrm{CI}) \text { P-value }\end{array}$ \\
\hline $\begin{array}{l}\text { Baseline LS-BMD }\left(\mathrm{mg} / \mathrm{cm}^{2}\right) \text {, } \\
\text { mean }(\mathrm{SD})\end{array}$ & 730.5 (II2.4) & $710.0(104.8)$ & & 722.9 (I44.2) & $725.2(135.6)$ & \\
\hline $\begin{array}{l}\text { Absolute value week } 24 \\
\left(\mathrm{mg} / \mathrm{cm}^{2}\right) \text {, mean }(\mathrm{SD})^{\mathrm{c}}\end{array}$ & $780.2(117.4)$ & $714.7(112.8)$ & & 748.1 (I70.3) & 738.7 (I25.0) & \\
\hline $\begin{array}{l}\text { Change from baseline }\left(\mathrm{mg} / \mathrm{cm}^{2}\right) \text {, } \\
\text { least squares mean }(95 \% \mathrm{Cl}) \\
P \text {-value }\end{array}$ & $\begin{array}{l}44.4(37.2-51.7) \\
<0.00 \mathrm{I}^{\mathrm{b}}\end{array}$ & $\begin{array}{l}10.5(1.2-19.9) \\
0.028^{b}\end{array}$ & $\begin{array}{l}33.9(22.4-45.4) \\
<0.00^{\mathrm{a}}\end{array}$ & $\begin{array}{l}57.5(40.2-74.9) \\
<0.00 \mathrm{I}^{\mathrm{b}}\end{array}$ & $\begin{array}{l}17.7(4.7-30.6) \\
0.009^{\mathrm{b}}\end{array}$ & $\begin{array}{l}39.9(20.7-59.0) \\
<0.00 \mathrm{I}^{\mathrm{a}}\end{array}$ \\
\hline $\begin{array}{l}\text { Percent change from baseline, } \\
\text { least squares mean }(95 \% \mathrm{Cl}) \\
P \text {-value }\end{array}$ & $\begin{array}{l}6.4(5.3-7.5) \\
<0.00 I^{b}\end{array}$ & $\begin{array}{l}1.4(0.0-2.8) \\
0.046^{b}\end{array}$ & $\begin{array}{l}5.0(3.2-6.7) \\
<0.00 \mathrm{I}^{\mathrm{a}}\end{array}$ & $\begin{array}{l}8.6(6.0-11.2) \\
<0.00 \mathrm{I}^{\mathrm{b}}\end{array}$ & $\begin{array}{l}3.2(1.3-5.1) \\
0.002^{b}\end{array}$ & $\begin{array}{l}5.4(2.5-8.2) \\
<0.00 \mathrm{I}^{\mathrm{a}}\end{array}$ \\
\hline
\end{tabular}

Notes: ${ }^{\mathrm{P}}$-value for teriparatide vs comparator using analysis of covariance adjusting for investigator and baseline LS-BMD. ${ }^{\mathrm{b}} \mathrm{Change}$ from baseline within each treatment arm was tested by paired $t$-test. ${ }^{~}$ Number of patients with missing data: teriparatide (Chinese) $=20$, calcitonin $=8$, teriparatide $($ FPT) $=79$, placebo $=84$.

Abbreviations: FPT, fracture prevention trial; LS-BMD, lumbar spine-bone mineral density. 
Table 4 Overview of safety, laboratory values, and bone markers in matched-pair patients over 24 weeks after randomization

\begin{tabular}{|c|c|c|c|c|}
\hline \multirow{2}{*}{$\begin{array}{l}\text { Preferred term }{ }^{a} \text { of all SAEs and TEAEs occurring } \\
\text { in } \geq 4 \% \text { of patients, } N(\%)\end{array}$} & \multicolumn{2}{|l|}{ Chinese study } & \multicolumn{2}{|l|}{ FPT } \\
\hline & $\begin{array}{l}\text { Teriparatide } \\
\mathrm{N}=148\end{array}$ & $\begin{array}{l}\text { Calcitonin } \\
\mathrm{N}=80\end{array}$ & $\begin{array}{l}\text { Teriparatide } \\
\mathrm{N}=107\end{array}$ & $\begin{array}{l}\text { Placebo } \\
\mathrm{N}=121\end{array}$ \\
\hline Death & 0 & 0 & 0 & $\mathrm{I}(0.8)$ \\
\hline Patients with $\geq I$ SAE & $7(4.7)$ & $\mathrm{I}(\mathrm{I} .3)$ & $8(7.5)$ & $12(9.9)$ \\
\hline Patients with $\geq$ I TEAE & $48(32.4)$ & $22(27.5)$ & $71(66.4)$ & $79(65.3)$ \\
\hline Dizziness & $10(6.8)$ & $3(3.8)$ & $9(8.4)$ & $7(5.8)$ \\
\hline Blood uric acid increased & $8(5.4)$ & 0 & 0 & 0 \\
\hline Muscle spasms & $8(5.4)$ & $4(5.0)$ & $2(1.9)$ & $2(1.7)$ \\
\hline Blood alkaline phosphatase increased & $6(4.1)$ & $\mathrm{I}(\mathrm{I} .3)$ & 0 & 0 \\
\hline Nasopharyngitis & $6(4.1)$ & $2(2.5)$ & $2(1.9)$ & $2(1.7)$ \\
\hline Nausea & $6(4.1)$ & 0 & $6(5.6)$ & $5(4.1)$ \\
\hline Pain in extremity & $6(4.1)$ & $2(2.5)$ & $2(1.9)$ & $3(2.5)$ \\
\hline Arthralgia & $4(2.7)$ & $\mathrm{I}(\mathrm{I} .3)$ & $4(3.7)$ & $9(7.4)$ \\
\hline Back pain & $4(2.7)$ & 0 & $5(4.7)$ & $6(5.0)$ \\
\hline Headache & $3(2.0)$ & $2(2.5)$ & $2(1.9)$ & $6(5.0)$ \\
\hline Asthenia & $2(1.4)$ & 0 & $5(4.7)$ & $3(2.5)$ \\
\hline Urinary tract infection & 0 & 0 & $7(6.5)$ & $7(5.8)$ \\
\hline \multicolumn{5}{|c|}{ Mean (SD)/median change from baseline to week 24 for laboratory values and bone markers } \\
\hline Alkaline phosphatase, $U / L^{b}$ & $\begin{array}{l}24.82(30.37) \\
19.00 * * * *\end{array}$ & $\begin{array}{l}-3.76(14.66) \\
-3.45^{*}\end{array}$ & $\begin{array}{l}12.23(19.89) \\
8.00 * * *\end{array}$ & $\begin{array}{l}0.30(13.43) \\
1.00\end{array}$ \\
\hline Serum calcium, $\mathrm{mmol} / \mathrm{L}^{\mathrm{b}}$ & $\begin{array}{l}0.08(0.20) \\
0.08^{* * * *}\end{array}$ & $\begin{array}{l}-0.03(0.16) \\
-0.01\end{array}$ & $\begin{array}{l}0.08(0.15) \\
0.08^{* * * *}\end{array}$ & $\begin{array}{l}-0.01(0.10) \\
-0.02\end{array}$ \\
\hline Inorganic phosphorus, $\mathrm{mmol} / \mathrm{L}^{\mathrm{c}}$ & $\begin{array}{l}0.05(0.19) \\
0.05^{*} * * *\end{array}$ & $\begin{array}{l}-0.06(0.17) \\
-0.05^{*}\end{array}$ & $\begin{array}{l}-0.01(0.17) \\
0.00\end{array}$ & $\begin{array}{l}0.02(0.16) \\
0.02\end{array}$ \\
\hline ALT/SGPT, U/L ${ }^{b}$ & $\begin{array}{l}-0.93(21.07) \\
-0.10\end{array}$ & $\begin{array}{l}0.99(7.86) \\
0.00\end{array}$ & $\begin{array}{l}0.21(12.09) \\
0.00\end{array}$ & $\begin{array}{l}-0.25(8.62) \\
1.00\end{array}$ \\
\hline AST/SGOT, U/L ${ }^{d}$ & $\begin{array}{l}3.00(19.40) \\
1.00\end{array}$ & $\begin{array}{l}3.93(9.18) \\
1.85^{*}\end{array}$ & $\begin{array}{l}-0.71(7.87) \\
-1.00 *\end{array}$ & $\begin{array}{l}-1.11(8.31) \\
0.00\end{array}$ \\
\hline Urea nitrogen, $\mathrm{mmol} / \mathrm{L}^{\mathrm{e}}$ & $\begin{array}{l}0.24(I .53) \\
0.4 I^{*}\end{array}$ & $\begin{array}{l}0.06(1.47) \\
0.17\end{array}$ & $\begin{array}{l}0.23(1.44) \\
0.20 * * *\end{array}$ & $\begin{array}{l}-0.19(1.20) \\
-0.20\end{array}$ \\
\hline Creatinine, $\mu \mathrm{mol} / \mathrm{L}^{\mathrm{b}}$ & $\begin{array}{l}0.17(10.88) \\
1.00\end{array}$ & $\begin{array}{l}-1.87(12.55) \\
-0.50\end{array}$ & $\begin{array}{l}0.19(8.67) \\
0.00\end{array}$ & $\begin{array}{l}-0.06(7.02) \\
0.00\end{array}$ \\
\hline Uric acid, $\mu \mathrm{mol} / \mathrm{L}^{\mathrm{b}}$ & $\begin{array}{l}62.55(73.20) \\
59.00^{* * * *}\end{array}$ & $\begin{array}{l}2.86(58.7) \\
1.50\end{array}$ & $\begin{array}{l}56.96(44.89) \\
53.53^{*}, * *\end{array}$ & $\begin{array}{l}0.10(34.56) \\
-4.00\end{array}$ \\
\hline
\end{tabular}

Notes: ${ }^{a}$ MedDRA (version 12.0). ${ }^{b}$ Number of patients with missing data: teriparatide $($ Chinese $)=19$, calcitonin $=8$, teriparatide $\left(\right.$ FPT) $=10$, placebo $=4$. ${ }^{\mathrm{N}}$ Number of patients with missing data: teriparatide (Chinese) $=21$, calcitonin $=10$, teriparatide $(F P T)=10$, placebo $=4$. ${ }^{d}$ Number of patients with missing data: teriparatide $($ Chinese) $=20$, calcitonin $=8$, teriparatide $(F P T)=10$, placebo $=4$. eNumber of patients with missing data: teriparatide $($ Chinese $)=21$, calcitonin $=8$, teriparatide $($ FPT $)=10$, placebo $=4$. $* P<0.05$ difference from baseline using Wilcoxon signed rank test. $* * P<0.05$ teriparatide vs comparator using Wilcoxon rank sum test.

Abbreviations: ALT/SGPT, alanine aminotransferase/serum glutamic pyruvic transaminase; AST/SGOT, aspartate aminotransferase/serum glutamic oxaloacetic transaminase; FPT, fracture prevention trial; SAE, serious adverse event; TEAE, treatment emergent adverse event; MedDRA, Medical Dictionary for Regulatory Activities.

similar increases in alkaline phosphatase, uric acid, and calcium were seen. In Chinese and Caucasian patients there were mild changes in phosphorus, ALT, AST, urea nitrogen, and creatinine that were not clinically significant.

\section{Long-term efficacy (19 months following randomization)}

Long-term data from matched-pair patients in FPT (Table 5), exhibited significantly increased mean LS-BMD from teriparatide treatment compared with placebo $(P<0.001)$. The least-squares mean $(95 \% \mathrm{CI})$ on absolute difference of LS-BMD between teriparatide and placebo groups from the baseline visit to last visit was $75.3 \mathrm{mg} / \mathrm{cm}^{2}$ (95\% CI: 61.4-89.2). The least-squares mean (95\% CI) on percent difference was $11.5 \%(95 \%$ CI: $9.2-13.8)$. The difference in the number of matched FPT patients who experienced a fragility fracture in the long-term analysis (Table 5) was numerically less compared to placebo, but the difference was not 
Table 5 Analysis of lumbar spine-bone mineral density and fragility fracture prevalence at endpoint (median 19.0 months) for patients from the FPT selected for matching

\begin{tabular}{|c|c|c|c|}
\hline & $\begin{array}{l}\text { Teriparatide } \\
\mathrm{N}=107\end{array}$ & $\begin{array}{l}\text { Placebo } \\
\mathbf{N}=|2|\end{array}$ & $\begin{array}{l}\text { Difference, least-squares } \\
\text { mean or OR plus }(95 \% \mathrm{Cl}) \\
\text {-value }^{\mathrm{a}}\end{array}$ \\
\hline Baseline LS-BMD $\left(\mathrm{mg} / \mathrm{cm}^{2}\right)$, mean (SD) & $722.9(144.2)$ & $725.2(135.6)$ & \\
\hline Value at last visit in FPT $\left(\mathrm{mg} / \mathrm{cm}^{2}\right)$, Mean $(S D)^{c}$ & $798.9(143.1)$ & $727.8(144.2)$ & \\
\hline $\begin{array}{l}\text { Absolute change from baseline }\left(\mathrm{mg} / \mathrm{cm}^{2}\right) \text {, } \\
\text { least-squares mean }(95 \% \mathrm{Cl}) \\
P \text {-value }{ }^{\mathrm{b}, \mathrm{c}}\end{array}$ & $\begin{array}{l}84.2(72.8,95.5) \\
<0.00 \text { I }\end{array}$ & $\begin{array}{l}8.9(-I . I, I 8.9) \\
0.081\end{array}$ & $\begin{array}{l}75.3(6 \mathrm{I} .4,89.2) \\
<0.00 \mathrm{I}^{\mathrm{d}}\end{array}$ \\
\hline $\begin{array}{l}\text { Percent change from baseline, least-squares } \\
\text { mean }(95 \% \mathrm{Cl}) \\
P \text {-value } \mathrm{e}^{\mathrm{b}, \mathrm{c}}\end{array}$ & $\begin{array}{l}12.7(|0.8,| 4.6) \\
<0.00 \mid\end{array}$ & $\begin{array}{l}1.2(-0.5,2.9) \\
0.158\end{array}$ & $\begin{array}{l}11.5(9.2,13.8) \\
<0.00 \mathrm{I}^{\mathrm{d}}\end{array}$ \\
\hline \multicolumn{4}{|l|}{ Fragility fracture, N (\%) } \\
\hline Yes & $14(13.1)$ & $27(22.3)$ & $0.59(0.32,1.06)$ \\
\hline No & $93(86.9)$ & $94(77.7)$ & $0.070^{\mathrm{e}}$ \\
\hline
\end{tabular}

Notes: ${ }^{P}$-value tested by analysis of covariance adjusting for investigator and baseline LS-BMD and chi-squared test for rates of fracture. ${ }^{b} P$-value tested by paired $t$-test. ${ }^{c}$ Number of patients with missing data: teriparatide $=9$, placebo $=5$. 'Least squares mean difference of teriparatide vs placebo. ${ }^{\mathrm{e} O R}$ of teriparatide vs placebo.

Abbreviations: FPT, fracture prevention trial; LS-BMD, lumbar spine-bone mineral density.

statistically significant: teriparatide $14 / 107,(13.1 \%)$; placebo 27/121, (22.3\%); RR: 0.59; 95\% CI: 0.32-1.06; $P=0.070$.

In an analysis of fracture incidence during the 19-month study duration in the entire FPT population $(\mathrm{N}=1,053)$, the OR $(95 \% \mathrm{CI})$ for fracture between the teriparatide and placebo groups was (OR: 0.43 ; $95 \%$ CI: $0.30-0.61 ; P<0.001$ ). Over 24 weeks, there were very few fractures in the entire population of the Chinese study ( $\mathrm{N}=325)$, which is inconclusive given the short duration of the study. However, after a pooled analysis of the 6-month Chinese study and the 19-month FPT, the OR ( $95 \% \mathrm{CI})$ for fracture between teriparatide and comparator groups in the full analysis set from both studies $(\mathrm{N}=1,378)$ was (OR: 0.36 ; $95 \%$ CI $0.25-0.51$; $P<0.001)$.

\section{Discussion and conclusion}

Teriparatide is a recombinant form of the parathyroid hormone that has been shown to decrease the risk of vertebral and nonvertebral fractures, increase bone mineral density, and have only minor side effects over a median treatment period of 19 months in a large international study of postmenopausal women with osteoporosis. ${ }^{15}$ Whether the shortand long-term results from this study can be extrapolated to a Chinese population was not known; in particular, the long-term effects of teriparatide on bone mass and fracture risk were not studied. In the present analysis, we compared results from a 24-week osteoporosis study in China to the FPT and found that data from matched-pair patients with osteoporosis from the two studies showed similar increases in least-squares mean of LS-BMD following 24 weeks of teriparatide treatment, and have a similar rate of TEAEs, SAEs, and change from baseline in specific laboratory values. The FPT showed a median treatment duration of 19 months, which is three times larger than that of the Chinese study and provided important information on further changes in LSBMD and the rate of fracture in the long-term. These results suggested that long-term results of the FPT could reasonably be extrapolated to a Chinese population.

There are known ethnic and racial differences in the incidence of osteoporosis and osteoporotic fractures throughout the world. ${ }^{16,17}$ In addition, genetic variability related to ethnicity is one factor that accounts for the observed differences in both pharmacokinetics and pharmacodynamics of drugs, resulting in variability in response to drug therapy. ${ }^{18-20}$ Bridging studies exist to allow safe approval of drugs in ethnically different nations without duplicating research efforts. This study utilized bridging methodology developed by the $\mathrm{ICH}$, a body that brings together regulatory authorities of Europe, Japan, and the United States, and experts from the pharmaceutical industry in the three regions. The ICH E5 guidelines were introduced in 1998 and, except for the development of Bayesian statistical methods to assess the degree of similarity, have remained unchanged since that time.

On comparing increase in LS-BMD after 24 weeks of teriparatide $20 \mu \mathrm{g}$ in Chinese and Caucasian patients, we found that both had significant $(P<0.001)$ increases compared to their comparator (calcitonin/placebo). Teriparatide is known to improve LS-BMD over time ${ }^{21}$ and the increases were of a similar magnitude $(5.0 \%$ in Chinese vs $5.4 \%$ in Caucasian) and were consistent with results from the entire 
population of each study $(5.0 \%$ at 24 weeks in the Chinese study and $9.7 \%$ at 19 months for the FPT). In a Japanese teriparatide bridging study, which compared 203 patients from a phase III randomized clinical trial to patients in the FPT, the difference between the teriparatide $20 \mu \mathrm{g}$ group and the placebo group in the percent change in LS-BMD from baseline to 12 months was $10.20 \%$ in the Japanese study and $7.41 \%$ in the FPT, thereby confirming superiority of teriparatide $20 \mu \mathrm{g}$ to placebo in both studies. ${ }^{22}$ Likewise, increase in LS-BMD was shown in a systematic review of ten randomized clinical trials of teriparatide $20 \mu \mathrm{g}$ for bonerelated conditions from China, Hong Kong, Japan, Republic of Korea, Philippines, Singapore, and Taiwan. ${ }^{23}$ Efficacy data was mainly taken from randomized clinical trials for treatment of postmenopausal osteoporosis and percent change in LS-BMD increased with increasing duration of treatment, from $4.3 \%$ at 24 weeks of treatment to greater than $10 \%$ at 18-24 months of treatment. This review provided an appraisal of the few long-term studies of teriparatide available in Asian patients.

Safety over 24 weeks was similar in the Chinese study and the FPT. Teriparatide was well tolerated and the only death was reported from the placebo group. ${ }^{11}$ SAEs occurred infrequently and individual SAEs tended to occur singularly. TEAEs were twice as likely to occur in FPT patients as in patients from the Chinese study. However, the similarity between relative risks for teriparatide versus comparator in both the Chinese trial and the FPT suggests that the differences in TEAE rates between studies may reflect differences in reporting systems, rather than differences in the action of the drug between ethnic groups. The changes in laboratory values from baseline following teriparatide treatment that were seen in both studies have been well documented in prior teriparatide trials. ${ }^{24}$ Teriparatide has been shown to induce modest but transient increases in serum calcium, which is consistent with the known effects of endogenous parathyroid hormone (PTH), and no unexpected safety findings were observed in patients who experienced hypercalcemia during treatment with teriparatide. The increase of alkaline phosphatase, calcium, and uric acid demonstrate pharmacologic response of teriparatide (similar to PTH) in both Chinese and Caucasian patients. Phosphorus had a clinically insignificant increase at week 24 in the Chinese study but not in the FPT. Also, the observed increases in both calcium and uric acid have been documented in the product insert and no nephrolithiasis was reported in either study. Both studies showed an increase in bone formation biomarkers reflecting bone formation over 12 weeks.
For the long-term analysis of paired patients in the FPT, the $P$-value for fracture reduction compared with placebo was 0.070 . The result was not significant, primarily because after matching, the sample size was markedly reduced. In this study, the proportion of matched patients from the FPT with fracture was $13.1 \%$ for teriparatide and $22.3 \%$ for placebo. Assuming there were roughly 120 patients in each study arm, the power to detect the statistically significant difference between two arms was $47 \%$.

Patients utilized in this comparison were chosen through a PS matching method. At baseline, patients selected by matching from the Chinese teriparatide study and the global FPT looked very similar, with no significant differences for standard baseline characteristics thought to be risk factors of osteoporosis that may influence the disease outcome (duration of osteoporosis, body mass index, etc). This met our expectations and suggested that we had created a model for PS matching that had successfully selected two groups of patients who were balanced in most of the risk factors except for ethnicity. However, the PS method only controls observed variables. Any hidden bias due to latent variables may remain.

These studies had two different comparators: placebo and calcitonin. Calcitonin is a weak antiresorptive agent; for example, at the end of 1 year, calcitonin $200 \mathrm{IU} /$ day increased LS-BMD by $<1.5 \%,{ }^{25}$ which is below the sensitivity of the test (estimated at 3\%). In our 24-week study, LS-BMD increased $1.4 \%$ after 6 months of calcitonin $200 \mathrm{IU}$ (compared with $6.5 \%$ in the teriparatide group). These differences seen with calcitonin treatment were minimal and would only marginally affect the results of this comparison.

A limitation of the current study was that the pharmacokinetics of teriparatide in these matched-pair patients were not compared because such parameters were not evaluated in the Chinese study as would be optimal per ICH E5 guidelines. A literature search revealed that a pharmacokinetic analysis of teriparatide had not been performed in Chinese versus Caucasian population. However, the pharmacokinetics of the $20 \mu \mathrm{g}$ dose was evaluated in 9 healthy Chinese volunteers ${ }^{26}$ and similar findings were obtained in a subgroup of 360 global patients from the FPT in whom pharmacokinetic parameters were measured. ${ }^{27}$ According to the package insert, teriparatide $20 \mu \mathrm{g}$, once daily has high bioavailability ( $~ 95 \%)$, rapid onset ( $\sim 30$ minutes), and short exposure $\left(\mathrm{t}_{1 / 2} \text { of } 1 \text { hour }\right)^{24}$ and these pharmacokinetic properties would not be expected to reduce drug availability in different ethnic groups. Tsujimoto et al analyzed data from healthy Japanese and Caucasian women with 
postmenopausal osteoporosis. ${ }^{22}$ This study compared results from the FPT to results from three Japanese studies, one of which included pharmacokinetic data. Findings from this bridging study concluded that there were no major differences in bodyweight-adjusted pharmacokinetics of teriparatide in Japanese patients and patients in the FPT. Chinese and Japanese populations feature similar regional geography and similar genes encoding drug-metabolizing enzymes and transporters. ${ }^{28}$ It may be reasonable to assume that they would have similar pharmacokinetic characteristics for teriparatide and, by extension, that pharmacokinetic parameters in Chinese patients would be similar to those of patients in the FPT.

Results of this analysis help fill the gap created by the lack of data from long-term head-to-head studies of teriparatide versus comparator in Chinese postmenopausal women. Weaknesses of this study include use of different comparators in the Chinese study (calcitonin) and the FPT (placebo), though at 24 weeks, calcitonin has been shown to have a placebo-like effect on LS-BMD in this population. ${ }^{29}$ In addition, the dose-response data were limited, and assumptions were made based on existing data in similar populations. We estimated the relative risk of teriparatide compared with comparator; however, we could not estimate the absolute risk, as there are different fracture rates in Chinese and Caucasian patients. Moreover, long-term Chinese fracture and safety data is desired to validate the findings from the bridging study.

In conclusion, this bridging study of patients with osteoporosis from two separate trials is the first one to compare Chinese and Caucasian populations. It showed similar increases in LS-BMD in Chinese and Caucasian patients following 24 weeks of therapy with teriparatide $20 \mu \mathrm{g}$ daily. This analysis, which conforms to ICH E5 guidelines, suggests that it might be reasonable to extrapolate the 19-month fracture results of the FPT to Chinese patients. Thus, longterm treatment with teriparatide would be expected to help reduce the risk of new fractures in Chinese women at a rate similar to that seen in other ethnic groups.

\section{Compliance with ethical standards}

Per the original publications for the Chinese study and the FPT, both had been approved by the appropriate institutional and/or national research ethics committee and had been performed in accordance with the ethical standards as laid down in the 1964 Declaration of Helsinki and its later amendments or comparable ethical standards. The patient consent forms were collected in both trials. For this post-hoc analysis by using existing data from the two original trials for research purpose, new formal consent is not required.

\section{Acknowledgment}

This study was funded by Eli Lilly and Company. The authors wish to thank Tao Wu of Eli Lilly for editorial assistance.

\section{Disclosure}

Zhongjian Xie has no conflicts of interest to disclose in this work. Yun Chen, Sirel Gurbuz, Bin Zhang, Yujie Li, Fan Bai, and Yu Chen are employees of and minor stock holders in Eli Lilly and Company.

\section{References}

1. Wade SW, Strader C, Fitzpatrick LA, Anthony MS, O'Malley CD Estimating prevalence of osteoporosis: examples from industrialized countries. Arch Osteoporos. 2014;9:182.

2. Chen P, Li Z, Hu Y. Prevalence of osteoporosis in China: a meta-analysis and systematic review. BMC Public Health. 2016;16(1):1039.

3. Compston JE. Skeletal actions of intermittent parathyroid hormone: effects on bone remodelling and structure. Bone. 2007;40(6):1447-1452.

4. Gallagher JC, Genant HK, Crans GG, Vargas SJ, Krege JH. Teriparatide reduces the fracture risk associated with increasing number and severity of osteoporotic fractures. J Clin Endocrinol Metab. 2005;90(3): $1583-1587$.

5. Orwoll ES, Scheele WH, Paul S, et al. The effect of teriparatide [human parathyroid hormone (1-34)] therapy on bone density in men with osteoporosis. J Bone Miner Res. 2003;18(1):9-17.

6. Greenspan SL, Bone HG, Ettinger MP, et al. Effect of recombinant human parathyroid hormone (1-84) on vertebral fracture and bone mineral density in postmenopausal women with osteoporosis: a randomized trial. Ann Intern Med. 2007;146(5):326-339.

7. Vestergaard P, Jorgensen NR, Mosekilde L, Schwarz P. Effects of parathyroid hormone alone or in combination with antiresorptive therapy on bone mineral density and fracture risk - a meta-analysis. Osteoporos Int. 2007; 18(1):45-57.

8. Barrett-Connor E, Siris ES, Wehren LE, et al. Osteoporosis and fracture risk in women of different ethnic groups. J Bone Miner Res. 2005; 20(2):185-194.

9. Naito C. Ethnic factors in the acceptability of foreign clinical data. Ther Innov Regul Sci. 1998;32(1):1283S-1292S.

10. Uyama Y, Shibata T, Nagai N, Hanaoka H, Toyoshima S, Mori K. Successful bridging strategy based on ICH E5 guideline for drugs approved in Japan. Clin Pharmacol Ther. 2005;78(2):102-113.

11. Dai K, Chen D, Zhang Z. Comparison of the effects of subcutaneous teriparatide and intranasal calcitonin in treating established osteoporosis in postmenopausal Chinese women. Chin J Osteoporos Bone Miner Res. 2011;4:23-31.

12. Neer RM, Arnaud CD, Zanchetta JR, et al. Effect of parathyroid hormone (1-34) on fractures and bone mineral density in postmenopausal women with osteoporosis. N Engl J Med. 2001;344(19): 1434-1441.

13. Liu Y, Ye K, Mathur AK, Hui S, Fuerst TP, Genant HK. Comparative calibration without a gold standard. Stat Med. 1997;16(16): 1889-1905.

14. Austin PC. An introduction to propensity score methods for reducing the effects of confounding in observational studies. Multivariate Behav Res. 2011;46(3):399-424.

15. Prevrhal S, Krege JH, Chen P, Genant H, Black DM. Teriparatide vertebral fracture risk reduction determined by quantitative and qualitative radiographic assessment. Curr Med Res Opin. 2009;25(4):921-928. 
16. Kanis JA, Johnell O, De Laet C, Jonsson B, Oden A, Ogelsby AK. International variations in hip fracture probabilities: implications for risk assessment. J Bone Miner Res. 2002;17(7):1237-1244.

17. Cauley JA. Defining ethnic and racial differences in osteoporosis and fragility fractures. Clin Orthop Relat Res. 2011;469(7):1891-1899.

18. Yasuda SU, Zhang L, Huang SM. The role of ethnicity in variability in response to drugs: focus on clinical pharmacology studies. Clin Pharmacol Ther. 2008;84(3):417-423.

19. International HapMap C. The international HapMap project. Nature. 2003;426(6968):789-796.

20. Wilson JF, Weale ME, Smith AC, et al. Population genetic structure of variable drug response. Nat Genet. 2001;29(3):265-269.

21. Obermayer-Pietsch BM, Marin F, McCloskey EV, et al. Effects of two years of daily teriparatide treatment on BMD in postmenopausal women with severe osteoporosis with and without prior antiresorptive treatment. J Bone Miner Res. 2008;23(10):1591-1600.

22. Tsujimoto M, Uenaka K, Iwata A, Higashiuchi Y, Sowa H. Effects of teriparatide in Japanese and non-Japanese populations: bridging findings on pharmacokinetics and efficacy. J Bone Miner Metab. 2012;30(3): 326-337.

23. Chen JF, Yang KH, Zhang ZL, et al. A systematic review on the use of daily subcutaneous administration of teriparatide for treatment of patients with osteoporosis at high risk for fracture in Asia. Osteoporos Int. 2015;26(1):11-28.
24. Forteo [package insert]. Indianapolis, IN: Eli Lilly and Company; 2016.

25. Chesnut $\mathrm{CH}$ 3rd, Silverman S, Andriano K, et al. A randomized trial of nasal spray salmon calcitonin in postmenopausal women with established osteoporosis: the prevent recurrence of osteoporotic fractures study. PROOF Study Group. Am J Med. 2000;109(4):267-276.

26. Chu NN, Li XN, Chen WL, Xu HR. Pharmacokinetics and safety of recombinant human parathyroid hormone (1-34) (teriparatide) after single ascending doses in Chinese healthy volunteers. Pharmazie. 2007; 62(11):869-871.

27. Satterwhite J, Heathman M, Miller PD, Marin F, Glass EV, Dobnig H. Pharmacokinetics of teriparatide (rhPTH[1-34]) and calcium pharmacodynamics in postmenopausal women with osteoporosis. Calcif Tissue Int. 2010;87(6):485-492.

28. Yi S, An H, Lee H, et al. Korean, Japanese, and Chinese populations featured similar genes encoding drug-metabolizing enzymes and transporters: a DMET Plus microarray assessment. Pharmacogenet Genom. 2014;24(10):477-485.

29. Hwang JS, Tu ST, Yang TS, Chen JF, Wang CJ, Tsai KS. Teriparatide vs. calcitonin in the treatment of Asian postmenopausal women with established osteoporosis. Osteoporos Int. 2006;17(3): $373-378$.
Clinical Interventions in Aging

\section{Publish your work in this journal}

Clinical Interventions in Aging is an international, peer-reviewed journal focusing on evidence-based reports on the value or lack thereof of treatments intended to prevent or delay the onset of maladaptive correlates of aging in human beings. This journal is indexed on PubMed Central, MedLine,

\section{Dovepress}

CAS, Scopus and the Elsevier Bibliographic databases. The manuscript management system is completely online and includes a very quick and fair peer-review system, which is all easy to use. Visit http://www.dovepress. com/testimonials.php to read real quotes from published authors. 